the notation which is described clearly, will become sufficiently familiar to make frequent reference to the glossary unnecessary.

It is not possible in small compass to do full justice to the author's grasp of the whole field of respiratory function and to his ingenuity in formulating its details without appearing fulsome. It is quite apparent that he has an equal grasp of the clinical aspects of his work and he illustrates the usefulness of the computer model as a teaching device over and over again. This is an important and stimulating book which amply repays the trouble of reading.

\section{Drug Therapy Reviews, Volume 1}

Edited by R. R. Miller \& D. J. Greenblatt. Pp. 260, illustrated. New York, Paris, Barcelona and Milan: Masson Publishing U.S.A.; Tunbridge Wells: Abacus Press, 1978. $£ 19.50$.

A consequence of the rapidly expanding number of drugs available for doctors to prescribe is the plethora of review articles, journals and books which attempt to give guidance on how, why and what to choose. Some, of course, are more impartial than others, and one could not wish for a more objective and unbiased assessment than the papers in this book which began 'as an effort to provide concise, up-to-date reviews of drug therapy to the staff of the New England Medical Centre in Boston, Mass.'. It is of high quality throughout, and some chapters, for example on narcotic analgesics, are outstanding examples of authoritative, factual and unequivocal advice. Others, such as those on procainamide and total parenteral nutrition have been overtaken by events, at least in this country, and herein lies a recurring problem, namely that many important effective drugs used by European doctors are not available in the U.S.A. and so find no mention here. This limitation, and a relatively high price will severely reduce its usefulness and appeal to British doctors.

\section{Essentials of Geriatric Medicine}

By George Adams. Pp. 98. Oxford, New York, Toronto: Oxford University Press, 1977. Soft cover $£ 1.95$.

This is the third edition revised and brought up to date, of the handbook which is based on lectures to undergraduate and postgraduate students. It gives a concise yet authoritative account of the more important medical problems of old age. The book is far from being comprehensive, but rather a selection of topics in which the author is especially interested. The book is divided into four parts. In the first he relates the basic data of ageing, describing the physio-pathological concepts of senescence.

Part two deals with the essentials of geriatric clinical practice, including discussion of such subjects as the implications of an ageing population, altered patterns of disease in old age, the definition of gerontology and geriatrics and geriatric clinical methods.

Part three contains chapters on common complaints in old age. Instead of describing systematically the disorders of old age, the author has selected the most important clinical syndromes, those which will be encountered by doctors, nurses, physiotherapists, social workers in their daily care of the elderly. There are excellent chapters on confusion, delirium, dementia, cerebro-vascular disease, Parkinsonism, diabetes, hypothermia, incontinence, pressure sores, malnutrition, metabolic bone diseases. As one would expect, the section on strokes and neurological disorders is especially informative. The subject of incontinence does not fill six pages, yet it contains the essential information which would be required by those who care for the elderly sick.

I am not convinced of the necessity of including in this part a chapter on terminal care of cancer patients. It is unlikely that many geriatric units will have to care for many of these patients especially if they are under sixty-five. It cannot be denied, though, that the ethical problems of prolonged dying, of control of pain, anxiety and depression, are subjects of immense importance to geriatricians and general physicians alike.

Professor Adams' writing is clear, makes it easy to understand, moreover the choice of topics is well balanced. The title of the book is well justified: the essentials of geriatric medicine are there. For those who wish to study extensively a given subject, a useful guide and selective bibliography are given. There is in addition a check-list for annual re-examination of long-stay geriatric patients and a subject index. All in all a very useful hand-book on geriatrics which I can highly recommend to medical students, young doctors and, in general, to all those caring for the elderly.

\section{Fundamentals of Obstetrics and Gynaecology}

Volume two: Gynaecology (2nd edn)

By Derex Llewellyn-Jones. Pp. 296, illustrated. London:

Faber \& Faber, 1978. Paperback $£ 6.95$. Hardback $£ 11.50$. When the first edition of this book appeared in 1970, it rapidly established itself as one of the best standard text books of gynaecology on account of the well written and authoritative nature of the text and the very clear accompanying photographs and charts. Particular emphasis was paid by the author to the medical and psychosomatic aspects of the subject whilst much less note was made of surgical techniques, it being felt rightly that these could best be learnt by observation.

The second edition now makes a welcome appearance and continues in the fine tradition of the first. There have been additions to many chapters, incorporating changes in management over the last few years; other chapters remain substantially the same. The chapter on human sexuality has been enlarged and rewritten as has the chapter on conception control and the author is to be congratulated on the very high quality of the illustrations, diagrams and flow charts. Despite the revision and enlargement of certain sections, there has only been an increase of 15 pages in the book; there has unfortunately been a sharp increase in price as a result of the ravages of inflation, but the book remains highly competitive and is very good value for money.

It is difficult to speak too highly of this textbook which not only succeeds in being clear, concise and well written but also makes reading it enjoyable.

\section{Hypoxia and Ischaemia. The Proceedings of a Symposium} Organized by The Royal College of Pathologists

Edited by BAsIL Morson. Pp. 190, illustrated. London: Royal College of Pathologists, 1977. Soft cover, inland £5.00. Abroad US $\$ 10.00$ incl. postage.

It is a tribute to the many distinguished contributors to this Symposium as well as to its editor and the Journal of Clinical Pathology that these proceedings have been published so swiftly. The contents can therefore be regarded as being as up to date as the printed word can ever be. The subject is highly topical and the contributions of physiologists, anaesthetists, physicians, surgeons and research workers in addition to specialist pathologists have resulted in a most successful interdisciplinary production, remarkably balanced and full of information.

The first chapters are general and relate to oxygen availability, tissue oxygenation and the biochemical consequences of hypoxia on energy production and on the functions of special organs. In the first of the chapters devoted to local topics Donald Heath reviews the mechanisms of hypoxic pulmonary hypertension including much of his own work at high altitude and the next chapter on hypoxia and the carotid body comes from the same school.

The pathology of myocardial ischaemia includes the 
physiology of intra-myocardial blood flow and the pathophysiology of infarction and sudden death. This depth includes a synthesis of the controversy over whether occlusive thrombi are always present in the coronary arteries supplying the territory of segmental infarcts (but it is a pity that there is no reference to the work either of Erhardt or of Fulton in this regard).

Ischaemia of bowel, bone and nerve and muscle are not neglected, nor the effects of hypoxia on tumour growth or the pathology of renal ischaemia and renal necrosis.

The mechanisms, prevention, treatment and consequences of hypoxia in the newborn infant and the pathology of perinatal hypoxia are authoritatively described. Finally we have four chapters devoted to the effects of hypoxia on the nervous system.

This paperback publication can be highly recommended and will have a wide appeal.

\section{Immunology of Gastrointestinal and Liver Disease}

By RALPH WRIGHT. Current Topics in Immunology Series. Pp. 132, illustrated. 1977. Soft cover $£ 4.75$.

This book is one of a series of monographs intended to provide the busy clinician with an up to date appraisal of the relevance of immunology to his own speciality. There are chapters on the basic physiology of the gut and liver as immunological organs, immune deficiency disorders, gastritis, coeliac disease, inflammatory bowel disease, acute and chronic hepatitis, drug and alcohol-induced liver disease, and tumour immunology. Throughout, the text is lucid and the illustrations, although simple, informative. Refreshing in a book of this kind is that the author treats controversial subjects without bias, refraining from dogmatizing with his personal views. The chapter on acute viral hepatitis gives a particularly clear account of the numerous antigens associated with hepatitis B (serum hepatitis) infection. Some unqualified statements are open to question, e.g. that there is no correlation between the presence of $\alpha$-foetoprotein and the hepatitis B surface antigen in hepatocellular carcinoma. Overall, however, the book admirably fulfils a need for the clinical gastroenterologist.

\section{Immunology of the Gut}

Ciba Foundation Symposium 46 (new series). Pp. viii +

376, illustrated. Amsterdam: Excerpta Medica, 1977.

Hard cover $\$ 28.75$ (Dfl. 70.00).

The gut is a potential site of entry for micro-organisms and antigens because absorptive function demands a permissive surface. It is therefore equipped with a large number of immunocytes residing in the lamina propria, the Peyer's patches and the mesenteric lymph nodes. The structural and functional features of this elaborate lymphoid system have until recently perhaps been somewhat neglected by experimental immunologists.

The CIBA symposium reported in this book brought together a well balanced group of 16 immunologists, pathologists and gastro-enterologists who reviewed the present state of knowledge of gut immunology and reported new experimental data. In his introduction the chairman, Professor Peter Lachmann, points out that interaction between immunology and clinical medicine has always very much been two-way, and this statement is well corroborated by the book. Most of the fifteen contributions are of high standard, and in their discussion after each contribution the participants often succeed in generating the type of multi-disciplinary interactions which amplify the data presented and reveal exciting areas for future research.

This is not a book for those who want a comprehensive review on the immunological features of gastro-intestinal diseases. Gastric and liver diseases are for instance not discussed and alimentary or food allergies hardly mentioned.
Indeed the few clinical chapters are not as good as those dealing with basic immunology.

The book makes considerable demands on background knowledge in immunology and research experience. It is highly recommended for both medical and non-medical immunologists and research-orientated gastro-enterologists but it is probably too specialized for the general physician.

\section{Intimations of Quality. Ante-mortem and Post-mortem} Diagnoses

By H. A. Waldron \& Lorna Vickerstaff. Pp. 59, illustrated. London: Nuffield Provincial Hospitals Trust, 1977. Soft cover, $£ 1.50$.

The post-mortem held its pre-eminent role up to the 1950 s. Since then increasing use of organ biopsy in life has contributed to its decline, but not without a struggle. There continues to be a spirited debate between those who regard the post-mortem room as the centre of the forum and those who prefer to assess the functional aspects of disease during life and correlate these with histology before it is too late to do so. This interesting Birmingham hospitals' study analyses the results of data entered on 1126 forms, specially designed so that the clinician completes the first part and the pathologist conducting the post-mortem fills the second part, both using the International Classification of Diseases. In less than $50 \%$ of the cases in this prospective study was the clinical diagnosis of cause of death confirmed at post-mortem. The remaining cases were almost equally split between those in which there was only a minor difference of opinion, and those in which disagreement was total. How so? Surely somebody must have been lying? Which is the suspect link in this clinico-pathological exercise? More important still, did the mistaken diagnoses shorten life? The reviewer does not want to spoil the mystery for the reader by revealing the solution so he recommends that the intellectually curious should dip into this splendid little paperback for a complete analysis and its therapeutic and epidemiological consequences.

Jamieson \& Kay's Textbook of Surgical Physiology (3rd edn). Edited by I. McA. Ledingham \& C. MacKay. Pp. 381, illustrated. Edinburgh, London and New York: Churchill Livingstone, 1978. £18.00.

Perhaps the most important feature of post-war surgical training is the emphasis which has been placed on the basic sciences. To-day's surgeon is not only required to be a skilled technician, but his art has to be firmly founded on the solid foundations of anatomy, pathology and physiology. The very first major hurdle which the trainee must encounter is the Primary Fellowship examination of one of the four Royal Colleges of Surgeons in these islands, in which his knowledge of these three subjects is rigorously tested. It is interesting that many of the great surgical teachers of recent times have themselves made fundamental contributions to our corpus of physiological knowledge and prominent among them is Sir Andrew Kay whose work on gastric secretion and the augmented histamine test is well known. Nearly 20 years ago, Professor Kay, together with his collaborator, Mr Ainslie Jamieson, published the first edition of this text book, which pioneered the standard texts dealing specifically with surgical physiology. This third edition, which appears after too long a gap, has been very completely rewritten. Now the original two authors have been joined by a large team of collaborators - mostly themselves surgeons, but also including physicians, oncologists and a biochemist - under the aegis of two new editors. The result is a completely up to date and readable text, well illustrated and providing an ideal volume for the surgeon in training. As well as covering the major physiological systems, circulation, respiratory system, endocrines, alimentary tract, nervous system and so on, there are specific chapters on wound healing, the biological effects of irradia- 